Jurnal Media Pertanian Vol. 2 No. 2 Tahun 2017 Hal. 92 - 97

Media Komunikasi Hasil Penelitian dan Review Literatur Bidang Ilmu Agronomi

ISSN print $2503-1279$ ISSN online $2581-1606$

\title{
TINGKAT SERANGAN HAMA PENGGEREK BUAH KAKAO \\ (Conopomorpha cramerella Snell.) (Lepidoptera: Gracillaridae) \\ DI DESA BETUNG KECAMATAN KUMPEH ILIR KABUPATEN MUARO JAMBI
}

\author{
Hayata \\ Program Studi Agroteknologi, Fakultas Pertanian Universitas Batanghari \\ Jl. Slamet Riyadi-Broni-Jambi, 36122 Telp. +62074160103 \\ email : hayatahayata82@gmail.com
}

\begin{abstract}
One of the barriers in the cacao caltivation is pest attacking of "hama penggerek Buah Kakao (PBK) that caused by conopomorpha cramerella. Cocoa pod was broke caused by PBK larvae by making a hole under the cover, beans and white pulp of cacao pod. It causes a hard cohering among beans and hard embedded the beans in its white pulp on an unripe cacao pod. The broken cocoa pod becomes wrinkled and emergence a dark color around the cocoa pod cover which resulting a decrease of weight and its quality.The attacking level was strongly determined by its farm maintenance conditions. This study aimed to know the attack level of cocoa pod in Betung Village, Muaro Jambi Regency.The studies had been started since June until August 2017.This research applies a survey method and completed by purposive sampling to find the sample. The sample location category was based on the more than four years of age and was being producting. The suffered cocoa pod sited around the tertiar branch of the plant that showed a very low intensity as much as 2,36 \%. The infected cocoa pods were located on all the part of the cocoa trees trunk e.g. the primary, secondary, and tertiary branchs which showed the very high intensity as much as 95,67\%. It's because of the farm passing on, where there is neither branches cutting down nor taking out the falling leaves and fruit on the ground; and also neither fertilizing nor pest controling.

Keywords : Attacking Intensity, fruit pest, conopomorpha cramerella
\end{abstract}

\begin{abstract}
Abstrak
Salah satu kendala dalam pengembangan tanaman kakao adalah serangan hama penggerek buah kakao (PBK) yang disebabkan oleh Conopomorpha cramerella. Kerusakan buah kakao disebabkan oleh larva PBK dengan cara membuat liang gerekan di bawah kulit buah dan di antara biji serta memakan daging buah. Pada buah yang relatif muda, hal itu menyebabkan biji melekat pada kulit buah dan melekat satu sama lain. Biji yang rusak mengeriput dan timbulnya warna gelap pada kulit biji yang mengakibatkan turunnya berat dan mutu produk. Tingkat serangan sangat ditentukan oleh kondisi pemeliharaan kebun. Penelitian ini bertujuan untuk mengetahui tingkat serangan penggerek buah kakao di Desa Betung Kabupaten Muaro Jambi. Penelitian telah dilakukan mulai bulan Juni sampai dengan Agustus 2017. Penelitian ini menggunakan metode survei dan pengambilan sampel secara purposive random sampling (metode acak terpilih). Kriteria menentukan lokasi sampel yaitu pertanaman kakao yang berumur lebih dari empat tahun dan telah berproduksi. Buah kakao yang terserang terletak pada cabang tersier dengan intensitas serangan yang sangat rendah yaitu sebesar 2,36 \%. Buah kakao yang terserang terletak pada semua bagian batang kakao yaitu di cabang primer, sekunder, dan tersier dengan intensitas serangan yang
\end{abstract}


Jurnal Media Pertanian Vol. 2 No. 2 Tahun 2017 Hal. 92 - 97

Media Komunikasi Hasil Penelitian dan Review Literatur Bidang Ilmu Agronomi

ISSN print $2503-1279$

ISSN online $2581-1606$

sangat tinggi yaitu sebesar 95,67\%. Kebun kakao dibiarkan begitu saja, tidak adanya pemangkasan terhadap cabang dan ranting, tidak adanya pembersihan terhadap daun buah yang gugur, tidak adanya pemupukan, dan juga tidak adanya pengendalian terhadap penggerek buah.

Kata kunci : Tingkat serangan, Penggerek buah, Conopomorpha cramerella

\section{PENDAHULUAN}

Indonesia telah tercatat sebagai negara penghasil kakao terbesar nomor tiga di dunia, sehingga produk kakaonya tidak diragukan lagi di kancah perdagangan internasional. Produksinya terus tumbuh rata-rata 3,5\% per tahun. Pada tahun 2010 produksi kakao Indonesia mencapai 574 ribu ton atau menyumbang $16 \%$ produksi kakao dunia, sedangkan Pantai Gading di peringkat pertama dengan 1,6 juta ton, atau menyumbang sebesar 44\% ( Nico, 2012).

Kecamatan Kumpeh Hulu Kabupaten Muaro Jambi merupakan daerah potensi yang sedang dikembangkan untuk budidaya kakao. Berdasarkan hasil survei memperlihatkan budidaya kakao dilakukan secara tradisional yang belum memenuhi persyaratan budidaya yang baik, termasuk juga sistem pengendalian hama terutama serangan hama penggerek buah, sehingga produksi yang dihasilkan belum maksimal.

Salah satu kendala dalam pengembangan tanaman kakao adalah serangan hama penggerek buah kakao (PBK) yang disebabkan oleh Conopomorpha cramerella. Sebelum PBK masuk menjadi hama baru pada perkebunan kakao di Indonesia pada bulan September 1994, yang menjadi hama utama kakao adalah kepik penghisap buah kakao Helopeltis theobromae. Hingga saat ini PBK masih sebagai hama penting pada pertanaman kakao di Filipina, Sulawesi Utara, Maluku Utara, Jawa, Sumatera Utara, dan Sabah (Malaysia). Akibat serangan PBK dapat menurunkan produksi sampai $80 \%$ dan kerusakan biji sampai 82\%, sehingga ditakuti oleh petani dan pengusaha perkebunan kakao (Pristiarini, 2012).

Kerusakan yang ditimbulkan oleh larva PBK berupa rusaknya biji, mengeriputnya biji dan timbulnya warna gelap pada kulit biji yang mengakibatkan turunnya berat dan mutu produk. Kerugian yang disebabkan oleh PBK merupakan resultante dari turunnya berat dan mutu produk serta meningkatnya biaya panen karena akan membutuhkan waktu cukup lama dalam pemisahan biji sehat dari biji yang rusak (Pristiarini, 2012).

Gejala serangan PBK mengakibatkan buah kakao berwarna agak jingga atau pucat keputihan, buah menjadi lebih berat dan bila diguncang tidak terdengar suara ketukan antara biji dengan dinding buah. Hal itu terjadi karena timbulnya lendir dan kotoran pada daging buah dan rusaknya biji-biji di dalam buah. Kerusakan daging buah akibat serangan PBK disebabkan oleh enzim heksokinase, malate dehidrogenase, fluorescent esterase dan malic polymorphisme yang disekresikan oleh PBK (Suparno, 2009)

Kerusakan buah kakao disebabkan oleh larva PBK dengan cara membuat liang gerekan di bawah kulit buah dan di antara biji serta memakan daging buah. Pada buah yang relatif muda, hal itu menyebabkan biji melekat pada kulit buah dan melekat satu sama lain, sedang pada buah matang tidak menimbulkan kerusakan berarti pada biji tapi dapat menurunkan mutu biji. Gerekan pada buah muda menyebabkan biji tidak berkembang, lebih-lebih apabila terjadi perusakan pada saluran makanan yang menuju biji (Wardojo, 1984). Serangan larva PBK pada buah bagian anterior akan 
Jurnal Media Pertanian Vol. 2 No. 2 Tahun 2017 Hal. 92 - 97

Media Komunikasi Hasil Penelitian dan Review Literatur Bidang Ilmu Agronomi

ISSN print $2503-1279$

ISSN online $2581-1606$

menyebabkan kerusakan lebih serius terhadap perkembangan biji atau bahkan menyebabkan pembusukan (Lim, 1984).

Serangan hama $C$. cramerella (PBK) menunjukkan tingkat serangan yang berbeda-beda. Hal ini disebabkan karena ketersediaan pakan yaitu buah kakao tetap ada di lapangan, sehingga memicu serangan hama tersebut di lapangan. Hama PBK yang menyerang tanaman kakao di perkebunan Rakyat Desa Betung Kumpeh Hulu merupakan hama utama yang menyebabkan turunnya produksi biji kakao. Hal ini disebabkan larva PBK menyerang buah kakao yang yang menyebabkan kerusakan biji kakao yang memiliki nilai ekonomis tinggi, sehingga serangan hama ini cukup merugikan. Untuk pegendalian serangan PBK diperlukan informasi tentang tingkat serangan.

\section{METODE PENELITIAN}

Penelitian dilakukan mulai bulan Juni sampai dengan Agustus 2017. Penelitian ini dilaksanakan di Desa Betung Kecamatan Kumpeh Hulu Kabupaten Muaro Jambi Propinsi Jambi dengan ketinggian tempat berkisar $5 \mathrm{~m}$ dpl. Pengamatan lebih lanjut terhadap buah dilakukan di Laboratorium Dasar Fakultas Pertanian Universitas Batanghari Jambi.

Bahan yang digunakan adalah tanaman Kakao (Theobroma cacao) di kebun rakyat, hama $C$. cramerella, label, karet dan kantong plastik. Alat yang digunakan adalah ember atau wadah, timbangan analitik,pisau scalpel, cawan, kaca pembesar, mikroskop, kalkulator dan kamera.

Penelitian ini menggunakan metode survey dan pengambilan sampel secara purposive random sampling (metode acak terpilih). Kriteria menentukan lokasi sampel yaitu pertanaman kakao yang berumur lebih dari empat tahun dan telah berproduksi

Pelaksanaan penelitian dimulai dari pemilihan lokasi kebun kakao di desa Betung yang akan dilakukan sebagai tempat penelititan. Areal pertanaman kakao dibagi atas 5 (lima) petak pengambilan sampel berdasarkan arah mata angin yaitu: Utara (T1), Selatan (T2), Timur (T3), Barat (T4) dan Tengah (T5). Masing-masing titik terdiri dari beberapa pohon dengan jumlah populasi sebanyak $10 \%$ dari seluruh populasi kebun kakao yang terbagi dalam 5 titik pengambilan sampel.

Setiap pohon sampel terdiri dari 4 ranting pengamatan. Pemberian label dilakukan pada setiap ranting yang menjadi bagian sampel pengamatan. Pengambilan data dilakukan dengan menghitung buah kakao pada ranting yang menjadi sampel kemudian menentukan nilai persentase serangan. Hama diidentifikasi dengan cara mengamati buah kakao dan biji yang terserang dengan menggunakan alat bantu loupe dan mikroskop.

Peubah yang diamati pada penelitian ini adalah letak buah terserang, intensitas serangan yang dihitung menggunakan rumus ;

$$
\begin{aligned}
& \text { Intensitas serangan PBK }(\%) \mathrm{I}=\frac{(\mathrm{Znx} \mathrm{z}) \mathrm{X} 100 \%}{\mathrm{~N} \mathrm{x} \mathrm{Z}} \\
& \text { Keterangan ; } \\
& \mathrm{N} \text { : Jumlah buah yang diamati } \\
& \text { Z: Kategori serangan tertinggi } \\
& \text { z: Kategori serangan pada buahke-i } \\
& \text { n: Buah contohke-i pada kategori z }
\end{aligned}
$$


Jurnal Media Pertanian Vol. 2 No. 2 Tahun 2017 Hal. 92 - 97

Media Komunikasi Hasil Penelitian dan Review Literatur Bidang Ilmu Agronomi ISSN print $2503-1279$

ISSN online $2581-1606$

Skoring kerusakan buah kakao akibat serangan PBK sebagai berikut:

0 : Buah mulus tak ada serangan

1 : Serangan ringan, biji masih bisa lepasdengan kulit

2 : Seragan sedang, biji agak sulit lepas dengan kulit

3 : Serangan berat, biji sulit dilepas dengan kulit

\section{HASIL DAN PEMBAHASAN}

\section{Letak Buah Yang Terserang}

Letak buah kakao yang terserang oleh $C$. cramerella hasilnya ditampilkan pada Tabel 1 berikut.

Tabel 1. Letak buah kakao yang terserang C. cramerella pada Perkebunan Kakao Rakyat Di Desa Betung Kumpeh Ulu

\begin{tabular}{cc}
\hline Kebun & Letak Buah yang Terserang \\
\hline Kebun 1 & Cabang Tersier \\
\hline Kebun 2 & Cabang Primer, Sekunder, dan Tersier \\
\hline Kebun 3 & Cabang Sekunder dan Tersier \\
\hline
\end{tabular}

Dari Tabel 1 diatas dapat diketahui bahwa pada Kebun 1, buah terserang $C$. cramerella hanya didapat pada buah yang terletak di cabang tersier (ranting) pada batang. Hal ini disebabkan pada Kebun 1 sistem pengendalian hama yang dilakukan sudah intensif, sehingga walaupun ada buah terserang hanya sedikit yang terletak pada bagian cabang tersier. Pada kebun 3 buah kakao yang terserang $C$. cramerella didapat di cabang sekunder dan cabang tersier.

Pada kebun 2 hampir semua buah kakao yang terdapat pada cabang primer dan cabang sekunder serta cabang tersier terserang $C$. cramerella. Hal ini disebabkaan tidak adanya sentuhan pengendalian hama, hal itu terlihat kebun kakao yang dibiarkan begitu saja tanpa ada perawatan terhadap tanaman kakao, sehingga dimanapun letak buah akan terserang oleh $C$. cramerella

\section{Intensitas Serangan}

Dari pengamatan yang telah dilakukan terhadap Intesitas serangan hama PBK di kebun kakao rakyat desa Betung Kumpeh Ulu, didapatkan hasilnya seperti tertera pada Tabel 2 berikut;

Tabel 2. Rerata Intensitas serangan hama Penggerek buah kakao pada Perkebunan Kakao Rakyat Di Desa Betung Kumpeh Ulu

\begin{tabular}{cc}
\hline Kebun & Intensitas serangan $(\%)$ \\
\hline Kebun 1 & 2,36 \\
\hline Kebun 2 & 95,67 \\
\hline Kebun 3 & 35,36 \\
\hline
\end{tabular}

Dari Tabel 2 dapat dilihat, bahwa intensitas serangan $C$. cramerella yang terjadi pada perkebunan kakao rakyat di desa Betung Kumpeh Ulu, telah memperlihatkan sistem perawatan kebun, yang dapat dibagi dalam tiga golongan perawatan Kebun Kakao. Pertama perawatan dengan sesungguhnya, kedua perawatan seadanya, dan yang ketiga tidak ada sentuhan perawatan. Pada kebun 1, kebun dirawat dengan sesungguhnya, hal itu diperlihatkan dari rendahnya intensitas serangan penggerek buah kakao yaitu sebesar $2,36 \%$. 
Jurnal Media Pertanian Vol. 2 No. 2 Tahun 2017 Hal. 92 - 97

Media Komunikasi Hasil Penelitian dan Review Literatur Bidang Ilmu Agronomi

ISSN print $2503-1279$

ISSN online $2581-1606$

Tindakan agronomi pada Kebun 1 yang telah dilakukan antara lain a) tanaman sudah berasal dari bibit okulasi dengan jarak tanam 4,5 x 4,5 m. b) Pemangkasan sudah dilakukan sedemikian rupa membentuk pohon yang baik dengan bentuk percabangan yang seimbang sehingga distribusi daun merata dalam penerimaan sinar matahari, kemudian menghilangkan cabang-cabang yang tidak perlu atau pun tidak dikehendaki. Misalkan saja tunas-tunas air, tunas-tunas sapu, cabang-cabang yang sakit, cabang-cabang yang kering, cabang-cabang yang tak dapat berasimilasi sendiri / cabang yang terlindungi, kemudian menjamin aerasi yang baik untuk mempertinggi produksi yang diperoleh. c) Pembersihan areal kebun, membersihkan daun dan buah yang jatuh pada lantai tanah. d) Pemupukan, dilakukan 2 kali dalam satu tahun sehingga tanaman dapat tumbuh dengan baik. e) Pengendalian hama dan penyakit dilakukan dengan secara mekanis, dan bila secara mekanis tidak bisa menanggulangi hama dan penyakit maka dilakukan tindakan penyemprotan menggunakan bahan kimia.

Kebun 3 intensitas serangan penggerek buah kakao sebesar 35,36\%, cukup tinggi intensitas serangan hal itu disebabkan pada Kebun 3 tanaman tidak terawat dengan baik, dan tindakan perawatan kebun dilakukan seadanya, yaitu terlihat dari cabang dan ranting yang tidak dipangkas dengan sempurna. Daun dan cangkang buah yang berserakan dan tidak dikelola dengan baik. Pengendalian hama dan penyakit yang hanya dilakukan seadanya. Penggunaan bahan kimia sebagai tindakan akhir pengendalian penggerek buah kakao dilakukan tidak pada saat yang tepat.

Kebun 2 intensitas serangan sebesar 95,67\%. Sangat tingginya intensitas serangan penggerek buah kakao pada kebun 2, hal itu disebabkan oleh tidak adanya tindakan perawatan yang dilakukan. Kebun kakao dibiarkan begitu saja, tidak adanya pemangkasan terhadap cabang dan ranting, tidak adanya pembersihan terhadap daun buah yang gugur, tidak adanya pemupukan, dan juga tidak adanya pengendalian terhadap penggerek buah.

\section{KESIMPULAN}

Berdasarkan hasil yang telah dibahas dapat disimpulkan bahwa, buah kakao yang terserang terletak pada cabang tersier dengan intensitas serangan yang sangat rendah yaitu sebesar 2,36 \%. Buah kakao yang terserang terletak pada semua bagian batang kakao yaitu di cabang primer, sekunder, dan tersier dengan intensitas serangan yang sangat tinggi yaitu sebesar $95,67 \%$

\section{DAFTAR PUSTAKA}

Lim, G. T.1984 . The Behavioural Studies on Cocoa Pod Borer Acrocercops cramerella Snellen. 9th International Cocoa Research Conference, Togo. (1984): 539-542.

Nico, A. 2012. 5 Komoditas Pertanian dan Perkebunan Yang Mendunia. http://nico03soil.wordpress.com/2012/11/06/5-komoditas-pertanian-danperkebunan- indonesia-Yang mendunia/. Diakses Tanggal 2 Januari 2017.

Pristiarini, W. 2012. Pengenalan Hama Penting Kopi dan Kakao.http://wanty npristiarini. blogspot.com/2012/01/laporan-7.html. Diakses Tanggal 2 Januari 2017.

Suparno, T. 1990. Perlindungan buah kakao dengan kantung plastik di Kebun Kakao ADC Kurotidur. Bengkulu Utara (Tidak dipublikasi). 
Jurnal Media Pertanian Vol. 2 No. 2 Tahun 2017 Hal. 92 - 97

Media Komunikasi Hasil Penelitian dan Review Literatur Bidang Ilmu Agronomi ISSN print $2503-1279$ ISSN online $2581-1606$

Wardojo, S. 1984. Kemungkinan pembebasan Maluku Utara daripada masalah penggerek buah cokelat Acrocercops cramerella Sn. Menara Perkebunan 52: 57-64

http://bbppketindan.bppsdmp.pertanian.go.id/blog/hama-pbk-pada-kakao 14 Pebruari 2017 